Rev. Bras. Saúde Prod. Anim., Salvador, v.16, n.4, p.772-783 out./dez.., 2015 http://www.rbspa.ufba.br ISSN 15199940

\title{
Variabilidade espacial das respostas produtivas e morfológicas do capim-Marandu em função dos atributos químicos e topográficos
}

\author{
Spatial variability of yield response and morphological Marandu grass depending on \\ the chemical and topographical.
}

\section{OLIVEIRA, Leonardo Bernardes Taverny $\mathrm{de}^{1^{*}}$; SANTOS, Antonio Clementino dos ${ }^{2}$; LIMA, Josevaldo dos Santos ${ }^{3}$; NEVES NETO, Durval Nolasco}

\author{
${ }^{1}$ Universidade Federal do Tocantins, Programa de Pós-Graduação em Ciência Animal Tropical, \\ Araguaína, Tocantins, Brasil. \\ ${ }^{2}$ Universidade Federal do Tocantins, Departamento de Zootecnia, Araguaína, Tocantins, Brasil. \\ ${ }^{3}$ Zootecnista, Ruraltins, Fortaleza do Tabocão, Tocantins, Brasil \\ *Endereço para correspondência: tavernyzoot@yahoo.com.br
}

RESUMO

Objetivou-se com este trabalho avaliar a variabilidade espacial das respostas produtivas e estruturais do capim Marandu em função das características químicas do solo e da topografia do terreno. O experimento foi conduzido em uma topossequência, na escola de Medicina Veterinária e Zootecnia. Foram avaliadas as variáveis V, CTC, $\mathrm{SB}, \mathrm{m}, \mathrm{pH}$, na profundidade de $0-20 \mathrm{~cm}$, profundidade efetiva, número de perfilhos $\left(\mathrm{m}^{2}\right)$, produção de matéria seca $\left(\mathrm{kg} \mathrm{ha}^{-1}\right)$, altura do dossel forrageiro $(\mathrm{cm})$. Foram coletadas 72 amostras em pontos georreferenciados em terreno declivoso. O solo foi classificado como Neossolo Quartzarênico Órtico na porção superior (Topo), Neossolo Litólico Eutrófico, no terço superior da encosta (ombro), Neossolo Litólico Eutrófico no terço médio da encosta (meia-encosta) e Neossolo Quartzarênico Hidromórfico no terço inferior (pedimento). Todas as variáveis avaliadas apresentaram dependência espacial com variogramas de estrutura bem definida. A pastagem apresentou heterogeneidade na morfologia do dossel em função da distribuição espacial da fertilidade do solo, resultando em dossel e produção de matéria seca mais elevada no topo e atingindo a menor produção no ombro da topossequência. $\mathrm{O}$ dossel forrageiro apresenta heterogeneidade na morfologia em função da distribuição espacial da fertilidade do solo e da profundidade efetiva, resultando na definição de duas zonas manejo: $1 \rightarrow$ topo e pedimento; e $2 \rightarrow$ ombro e meia encosta.

Palavras-chave: Brachiaria brizantha, geoestatística, topossequência, vertente

\section{SUMMARY}

This work aimed to evaluate the spatial variability of structural and productive responses of Marandu grass depending on the chemical characteristics of the soil and topography. The experiment was conducted in a topossequence, school of Veterinary Medicine and Animal Science, The $\mathrm{V}$ variables were evaluated CTC, SB, m, pH at a depth of 0-20 $\mathrm{cm}$, effective depth, number of tillers $(\mathrm{m} 2)$, production dry matter ( $\mathrm{kg}$ ha-1), when sward (cm). 72 samples were collected in georeferenced points on sloping ground. The soil was classified as Entisol in the upper portion (top), Udorthent Eutrophic the upper third of the slope (shoulder), Udorthent eutrophic in the middle third of the slope (halfslope) and Quartzips amment Hydromorphic in the lower third (pedimento). All variables presented spatial dependence with variograms of well-defined structure. The pasture presented heterogeneity in the morphology of the canopy due to the spatial distribution of soil fertility, resulting in canopy and producing higher dry matter at the top and reaching the lower production on the shoulder of topossequence. The sward has heterogeneity in morphology depending on the spatial distribution of soil fertility and the effective depth, resulting in the creation of two management areas: $1 \rightarrow$ topo and pediment, and $2 \rightarrow$ shoulder and half hillside.

Keywords: Brachiaria brizantha, geostatistics, slope, toposequence 
Rev. Bras. Saúde Prod. Anim., Salvador, v.16, n.4, p.772-783 out./dez.., 2015 http://www.rbspa.ufba.br

\section{INTRODUÇÃO}

As áreas de pastagens, por mais bem manejadas que sejam, costumam apresentar heterogeneidade espacial na conformação estrutural do pasto como reflexo das características químicas do solo, podendo este problema ser ainda mais acentuado quando as pastagens são estabelecidas em áreas declivosas (ARTUR et al., 2014). O declive potencializa o deslocamento de nutrientes, que são conduzidos pelo deflúvio encosta abaixo resultando em maior estratificação da fertilidade.

A dependência espacial da fertilidade no ecossistema solo é influenciada pelos fatores de formação (relevo, clima, temperatura e umidade) e, ao manejo empregado (MIGUEL et al., 2009; ZANÃO JÚNIOR et al., 2010), refletem profundamente na característica de acúmulo de massa e crescimento, o que dependendo da magnitude do efeito, da variabilidade no teor da concentração de cada elemento e exploração do perfil do solo em profundidade, podem influir em modificações no dossel forrageiro $\mathrm{e}$ afetar diretamente no manejo e no aproveitamento do pasto. Portanto, o comportamento morfológico de crescimento, perfilhamento e produção de matéria seca do pasto é de caráter espacial (SANTOS et al., 2010).

O comportamento de crescimento e valor nutricional das plantas acompanha a variabilidade distributiva dos nutrientes (CAVALLINI et al., 2010). A altura do pasto reflete perfeitamente as relações da forrageira com os atributos do solo e pode ter o efeito acentuado de acordo com as relações intraespecíficas da superfície do horizonte agrícola com a rizosfera (ARTUR et al., 2014). A altura do dossel será aumentada e terá maior heterogeneidade do pasto (SCHWARTZ et al., 2003), tanto em termos quantitativos quanto qualitativos (GOMES et al, 2009).

$\mathrm{O}$ estudo de permuta dos elementos no solo por pontos regionalizados possibilita a compreensão do comportamento da variação espacial dos atributos químicos do solo no ecossistema pastoril e permite a exploração mais racional dos fatores de produção e a melhora na eficiência operacional e econômica de insumos (PARFITT et al., 2009).

O estudo da variabilidade dos atributos químicos do solo e das características morfológicas e produtivas das pastagens possibilita o diagnóstico preciso na orientação do uso eficiente do solo e, consequentemente, na formação de zonas de manejo (DAVATGAR, et al., 2012). O zoneamento baseado na variabilidade da fertilidade do solo e dos fatores morfológicos da forragem possibilita a aplicação localizada de insumos e a uniformização do pasto como um todo.

Objetivou-se com este trabalho avaliar a variabilidade espacial das respostas produtivas e estruturais do capim Marandu em função das características químicas do solo e da topografia do terreno.

\section{MATERIAIS E MÉTODOS}

O experimento foi conduzido no município de Araguaína (TO), localizado nas seguintes coordenadas geográficas, $07^{\circ} 06^{\prime} \mathrm{S}$ e $-48^{\circ} 11^{\prime} \mathrm{O}$. O clima da região foi classificado segundo Koppen como quente e úmido (AW). Os dados climatológicos de precipitação pluviométrica mensal $(\mathrm{mm})$ e temperatura média $\left({ }^{\circ} \mathrm{C}\right)$ foram coletados na estação climatológica principal de Araguaína, localizada na Escola de Medicina Veterinária e Zootecnia, campus da 
Rev. Bras. Saúde Prod. Anim., Salvador, v.16, n.4, p.772-783 out./dez.., 2015 http://www.rbspa.ufba.br

Universidade Federal do Tocantins, e são apresentados na Figura 1.

O solo foi classificado como Neossolo Quartzarênico Órtico na porção superior (Topo), Neossolo Litólico Eutrófico, no terço superior da encosta (ombro), Neossolo Litólico Eutrófico no terço médio da encosta (meia-encosta) e Neossolo Quartzarêncio Hidromórfico no terço inferior (pedimento) classificado segundo o Sistema Brasileiro de Classificação de Solos (EMBRAPA, 2006). Os resultados da análise descritora dos solos da área avaliada estão na Tabela 1.
A área útil experimental consiste de um total de $6000 \mathrm{~m}^{2},(20 \times 300 \mathrm{~m})$, na qual foi implantada com capim Uroclhoa brizantha cv. Marandu (Syn. Brachiara brizantha cv Marandu).

O solo da área foi preparado de forma convencional, consistindo de correção do solo com o uso de calcário dolomítico $\left(1,5 \mathrm{t} \quad \mathrm{ha}^{-1}\right)$, adubação fosfatada em fundação (superfosfato simples) com adição de $60 \mathrm{~kg} \mathrm{ha}^{-1} \mathrm{de}$ $\mathrm{P}_{2} \mathrm{O}_{5}$ incorporado e adubação potássica (cloreto de potássio) em superfície com adição de $80 \mathrm{~kg} \mathrm{ha}^{-1}$ de $\mathrm{K}_{2} \mathrm{O}$.

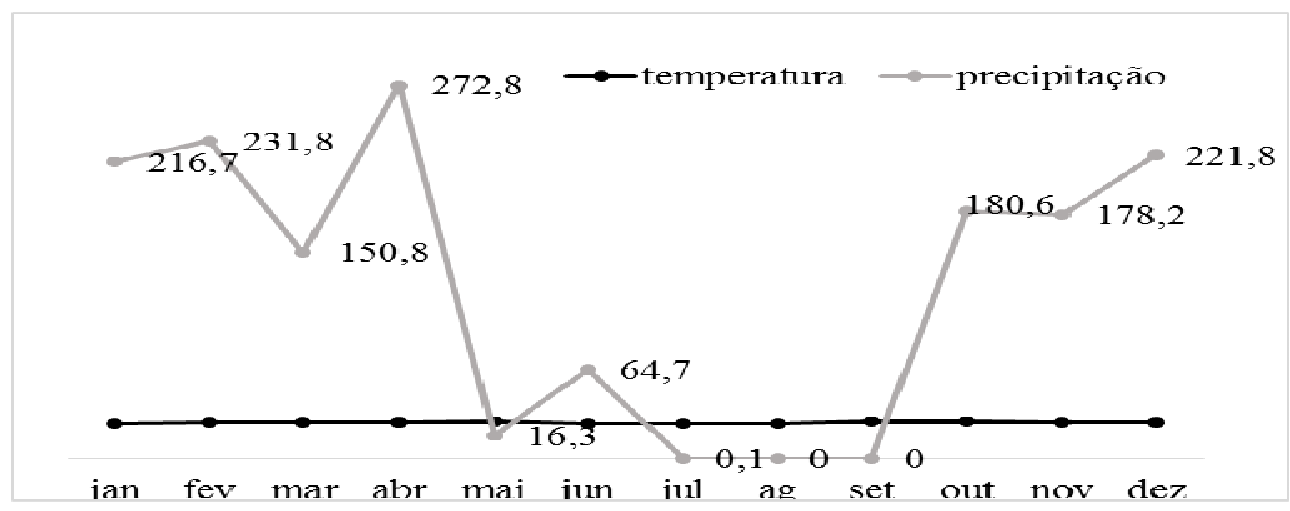

Figura 1. Precipitação mensal (mm) e temperatura média nos meses de janeiro a dezembro de 2010. Estação Climatológica Principal de Araguaína. Escola de Medicina Veterinária e Zootecnia da Universidade Federal do Tocantins, Araguaína/TO

Tabela 1. Valores da análise química e física descritora do solo nas quatro posições da topossequência

\begin{tabular}{|c|c|c|c|c|c|c|c|c|c|c|c|}
\hline $\mathrm{pH}$ & $\mathrm{Ca}$ & $\mathrm{Mg}$ & $\mathrm{Al}$ & $\mathrm{H}+\mathrm{Al}$ & $\mathrm{K}$ & P(Mel.) & M.O. & Arg. & Silt. & Areia & $\mathrm{V}$ \\
\hline $\mathrm{CaCl}_{2}$ & $\begin{array}{ll}----- \\
-\end{array}$ & $\mathrm{cmol}$ & -3 & 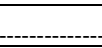 & \multicolumn{3}{|c|}{$---\mathrm{mgdm}^{-3}$} & \multicolumn{4}{|c|}{ 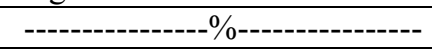 } \\
\hline \multicolumn{12}{|c|}{ Topo } \\
\hline 4,3 & 1,9 & 2,4 & 0,8 & 5,7 & 0,33 & 0,7 & 23,5 & 3,2 & 5,6 & 89,9 & 43 \\
\hline \multicolumn{12}{|c|}{ Ombro } \\
\hline 4,0 & 3,0 & 4,7 & 4,9 & 7,6 & 1,40 & 0,8 & 21,2 & 3,7 & 11,2 & 77,8 & 56 \\
\hline \multicolumn{12}{|c|}{ Encosta superior } \\
\hline 4,3 & 2,6 & 3,4 & 1,0 & 5,2 & 0,22 & 0,7 & 26,5 & 2,8 & 7,2 & 82,7 & 54 \\
\hline \multicolumn{12}{|c|}{ Pedimento } \\
\hline 4,4 & 1,9 & 2,4 & 0,3 & 5,0 & 0,16 & 0,8 & 37,7 & 3,1 & 5,9 & 88,7 & 46 \\
\hline
\end{tabular}

Mel: extração em mehlich-1. 
A área foi dividida em quatro segmentos: Topo (planalto), ombro (terço superior da encosta), meia encosta (terço médio da encosta) e pedimento (terço inferior da encosta) (Figura 1). O topo é delimitado pela convexidade de inclinação de $4 \%$, onde se inicia o ombro. A área de implantação do experimento inicia-se com uma área de topo com 23 metros lineares de terreno plano com declividade de $1 \%$ e profundidade efetiva de $1,50 \mathrm{~m}$, na porção de ombro declive de $8 \%$ e profundidade efetiva de $17 \mathrm{~cm}$ na porção média do terreno. $\mathrm{Na}$ porção de meia encosta superior, correspondente a $10 \%$ de declive e $0,70 \mathrm{~cm}$ de profundidade efetiva, no terço inferior da encosta a declividade foi $4 \%$ e profundidade efetiva de $1,85 \mathrm{~m}$. Para avaliações no solo, foram realizadas as coletas do solo na profundidade de $0-20 \mathrm{~cm}$, no mês de janeiro. A coleta foi procedida em malha irregular ao longo do declive, perfazendo um total de 72 pontos georreferenciados. Após a coleta do solo, as amostras foram encaminhadas para o laboratório de solo do curso de Zootecnia da Escola de Medicina Veterinária e Zootecnia, onde foram secas a sombra, peneiradas em malha de $2,0 \mathrm{~mm}$ (terra fina seca ao ar). $\mathrm{O} \mathrm{pH}$ em $\mathrm{CaCl}_{2} \quad 0,01 \quad \mathrm{M}$ foi determinado potenciometricamente em peagâmetro. $\mathrm{Ca}^{2+}, \mathrm{Mg}^{2+}$ e $\mathrm{Al}^{3+}$ trocáveis foram extraídos com solução de $\mathrm{KCl}$ a $1 \mathrm{~mol}$ $\mathrm{L}^{-1}$ e determinados pelo método complexométrico com emprego de EDTA $0,0125 \mathrm{~mol} \mathrm{~L}^{-1}$. Os valores de fósforo e potássio disponível foram extraídos pela solução de Mehlich-1, o $\mathrm{P}$ foi determinado por colorimetria em espectrofotômetro e $\mathrm{K}^{+}$em fotômetro de chama por fotocolorimetria. A acidez potencial $\left(\mathrm{H}^{+}+\mathrm{Al}^{3+}\right)$ foi extraída com solução de acetato de cálcio $0,5 \mathrm{~mol} \mathrm{~L}^{-1}$ e determinada por titulação com $\mathrm{NaOH}$
$0,025 \mathrm{~mol} \mathrm{~L}^{-1}$. Com base nos valores dos elementos analisados, foi determinada a saturação do solo (V \%) (EMBRAPA, 1999).

A profundidade efetiva do solo foi determinada com o auxílio de uma cavadeira manual que foi usada para escavar o solo verticalmente até atingir o horizonte $\mathrm{C}$ (rochas em decomposição). Após estabelecer a trincheira, a mesma foi medida com uma trena.

O capim Uroclhoa brizantha cv. Marandu (Syn. Brachiaria brizantha) foi semeado a lanço em dezembro de 2009. As avaliações na forrageira iniciaram no início do mês de março 2010. Inicialmente, foi realizado o pastejo de uniformização com entrada de animais, durante cinco dias, tempo determinante para obter-se altura de $15 \mathrm{~cm}$ de resíduo pós-pastejo. Três dias após o pastejo, foi realizada adubação nitrogenada (ureia) aplicando $50 \mathrm{~kg} \mathrm{ha}^{-1}$ de nitrogênio, e 32 dias após isolamento da área iniciaram as avaliações e coleta $\mathrm{da}$ forrageira. $\mathrm{O}$ segundo ciclo do pastejo foi o período que concentraram as avaliações da forrageira, que correspondeu da saída a uma nova entrada dos animais na área, os quais entraram após o pasto atingir 4,5 folhas surgidas em média, método realizado em toda área desde o topo até 0 pedimento.

Para determinação da matéria seca, a forragem foi coletada em cada ponto georreferenciado a campo, com auxílio de uma moldura de metal de $0,6 \mathrm{~m}^{2}(0,5$ $\mathrm{x} 1,20 \mathrm{~m})$, cortando-se a $5 \mathrm{~cm}$ do nível do solo. Em seguida, as amostras foram alocadas em sacos plásticos e encaminhadas para o laboratório onde foram realizadas as pesagens de material fresco. Após a pesagem de material total, uma alíquota era retirada e alocada em saco de papel e encaminhada para estufa de ventilação 
Rev. Bras. Saúde Prod. Anim., Salvador, v.16, n.4, p.772-783 out./dez.., 2015 http://www.rbspa.ufba.br

forçada a $55^{\circ} \mathrm{C}$ por 72 horas. Após determinação da matéria pré-seca, o material da alíquota foi processada em moinho tipo Willey em peneira de $1 \mathrm{~mm}$ e encaminhada para secagem definitiva a $105^{\circ} \mathrm{C}$. A altura média do dossel foi determinada com o uso de uma régua graduada em cinco locais de cada ponto georreferenciado (Figura 2).

Com o auxílio de uma moldura de $0,2 \mathrm{x}$ $1,5 \mathrm{~m}$, foi obtido o número de perfilhos por $\mathrm{m}^{2}$. A moldura foi colocada sob o dossel e a contagem de todos os perfilhos dentro da moldura foi efetuada.

A variabilidade espacial dos elementos do solo foi determinada através da análise exploratória dos dados determinando média, mediana, desviopadrão, coeficientes de curtose e assimetria. O teste de normalidade das variáveis foi realizado para verificar a distribuição normal dos dados através do teste de Shapiro-Wilk.

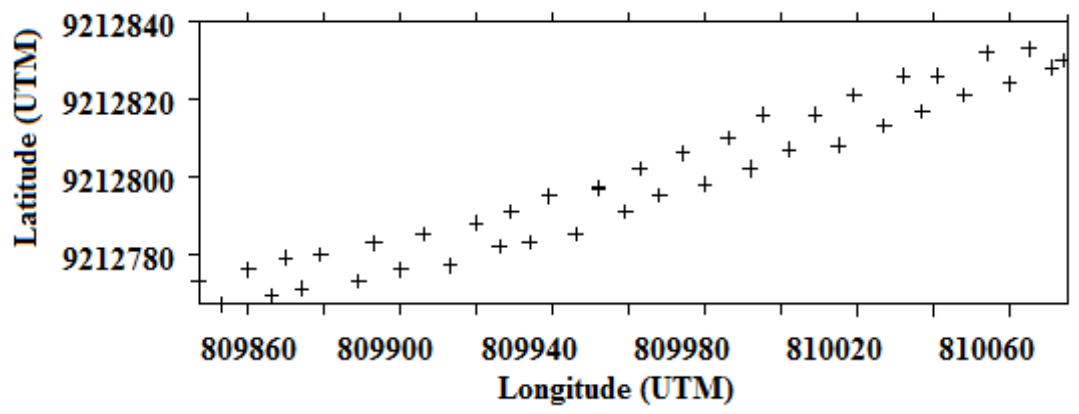

(A)

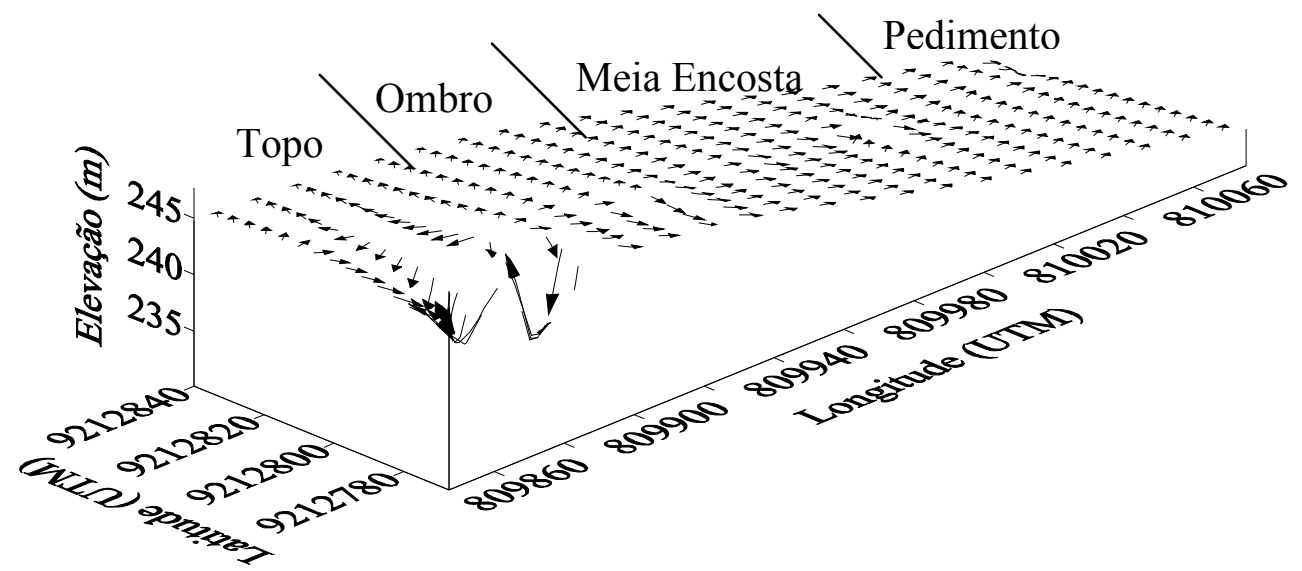

Figura 2. Localização georreferenciada dos pontos em malha irregular, das áreas cultivadas com capim Marandu (A). Topografia do terreno em estudo como mapa vetorial, vetores indicando a direção do deflúvio e o sentido da linha de amostragem côncava ao centro $(\mathbf{B})$

A dependência espacial foi determinada através da geoestatística pela interpretação e ajuste dos componentes variográficos confeccionados pelo software GS+ 5.1. Segundo Zimback et al. (2001), o Grau de Dependência Espacial (GDE) possui razões de classificação, em que $<25 \%$ indica 
Rev. Bras. Saúde Prod. Anim., Salvador, v.16, n.4, p.772-783 out./dez.., 2015 http://www.rbspa.ufba.br

dependência espacial fraca, moderada entre 25 a $75 \%$ e forte $>75 \%$. O grau de dependência espacial é obtido pela relação efeito pepita/patamar.

Os modelos de semivariância ajustados no sofware GS+ 5.1 (ROBERTSON, 1998) foram utilizados para elaboração dos mapas de isolinhas utilizando a técnica da Krigagem, através do software SURFER 8.0.

Os modelos foram selecionados e ajustados levando em consideração o coeficiente de determinação $\left(\mathrm{R}^{2}\right)$, a soma dos quadrados totais (SQR) e o critério da validação cruzada.

\section{RESULTADOS E DISCUSSÃO}

Os resultados da análise descritiva encontram-se na Tabela 2. Dentre os valores apresentados, somente profundidade efetiva do solo e saturação por alumínio expressaram ampla variação dos valores em torno da média e mediana. O reflexo desse efeito é demonstrado pelo coeficiente de variação, que foram substancialmente elevados. Coeficiente de variação elevado é o primeiro indicativo da heterogeneidade dos dados da variável (CAMPOS, et al., 2007). Isto sugere que a distribuição dos teores de nutrientes na área foram heterogêneos, causa que pode estar associada às influências de formação e deslocamento de nutrientes no relevo, como sugere Artur et al. (2014).

Embora para algumas variáveis os valores de máximo e mínimo sejam bastante acentuados, estes não foram suficientes para afetar a normalidade da distribuição dos desvios de assimetria (CAMBARDELLA et al., 1994), permitindo que os valores possam ser submetidos à análise geoestatística (ARTUR et al., 2014), mesmo para atributos tais como saturação por alumínio e profundidade efetiva, os quais apresentaram grande amplitude entre valores que poderiam afetar a distribuição.

Tabela 2. Valores da estatística descritiva das variáveis químicas e profundidade efetiva do solo e das variáveis altura, produção de matéria seca e perfilhamento da forrageira da área cultivada com Urochloa brizantha cv. Marandu na profundidade $0-20 \mathrm{~cm}$

\begin{tabular}{|c|c|c|c|c|c|c|c|c|}
\hline Variáveis & Méd & Med. & Max. & Mín. & DP. & Ass. & Curt. & $\mathrm{C}$ \\
\hline \multicolumn{9}{|c|}{ Capim 0-20 cm } \\
\hline $\mathrm{V}(\%)^{\mathrm{N}}$ & 45 & 44,76 & 56 & 33 & 5,66 & 0,19 & 2,55 & 12 \\
\hline $\mathrm{SB}^{\mathrm{N}}\left(\mathrm{cmol}_{\mathrm{c}} \mathrm{dm}^{-3}\right)$ & 5,5 & 5,17 & 10 & 3,0 & 1,92 & 0,63 & 2,69 & 34 \\
\hline $\mathrm{CTC}^{\mathrm{N}}\left(\mathrm{cmol}_{\mathrm{c}} \mathrm{dm}^{-3}\right)$ & 12 & 11,25 & 22 & 8,0 & 3,39 & 1,12 & 3,65 & 28 \\
\hline $\mathrm{m}(\%)^{\mathrm{N}}$ & 10,6 & 6,75 & 33 & 2,0 & 9,20 & 1,37 & 3,53 & 86 \\
\hline $\mathrm{pH}^{\mathrm{N}}\left(\mathrm{CaCl}_{2}\right)$ & 4,28 & 4,36 & 5,0 & 4,0 & 0,45 & 0,94 & 1,90 & 10 \\
\hline $\mathrm{MS}^{\mathrm{N}}\left(\mathrm{kg} \mathrm{ha}^{-1}\right)$ & 2431 & 2318 & 4036 & 1006 & 875 & 0,38 & 2,15 & 36 \\
\hline Altura ${ }^{\mathrm{N}}(\mathrm{cm})$ & 34,8 & 35,5 & 42 & 25 & 4,22 & $-0,45$ & 2,67 & 12 \\
\hline P. $\left(\mathrm{m}^{2}\right)$ & 173 & 165 & 294 & 98 & 55 & 0,41 & 2,08 & 32 \\
\hline P.E. ${ }^{N}(\mathrm{~cm})$ & 450 & 417 & 1190 & 90 & 218 & 0,51 & 2,56 & 48 \\
\hline
\end{tabular}

$\mathrm{V}(\%)=$ saturação por bases, $\mathrm{SB}=$ soma de Bases $\left(\mathrm{cmol}_{\mathrm{c}} \mathrm{dm}^{-3}\right), \mathrm{CTC}\left(\mathrm{cmol}_{\mathrm{c}} \mathrm{dm}^{-3}\right)=$ capacidade de troca catiônica, $\mathrm{m}(\%)=$ saturação por alumínio, $\mathrm{MS}=$ matéria Seca $\mathrm{kg} \mathrm{ha}^{-1}, \mathrm{P} .=$ número de perfilhos $\mathrm{m}^{-2}$, altura $(\mathrm{cm})$, P.E. $=$ Profundidade Efetiva do solo $(\mathrm{cm})$. Méd $=$ média, Med: mediana, Max $=$ valores máximos, Mín = valores mínimos, $\mathrm{DP}=$ desvio Padrão, $\mathrm{CV}=$ Coeficiente Variação $(\%), \mathrm{N}=$ indica normalidade na distribuição da variável. 
Baseada na autocorrelação de valores médios de pontos amostrais, a krigagem necessita de médias de elevada acurácia, o que pressupõe que distribuições assimétricas com caudas alongadas não são desejáveis (ISAAKS \& SRIVASTAVA, 1989). Portanto, a assimetria torna-se mais importante que a normalidade dos dados das variáveis.

A assimetria torna-se mais sensível a valores extremos, o que provoca um grande alongamento na calda da distribuição, entretanto o distanciamento dos valores extremos é acompanhado por valores sucessivamente próximos ao longo do eixo, auxiliando em um ajuste mais simétrico possível (ISAAKS \& SRIVASTAVA, 1989).

Todas as variáveis apresentaram dependência espacial forte, com exceção do $\mathrm{pH}$ que mostrou moderada dependência espacial.

Em todas as variáveis analisadas, a descontinuidade na origem foi pequena, fato que prevaleceu grande distância entre o efeito pepita e o patamar e, consequentemente, maior estruturação no variograma. Entretanto, as variações atribuídas a fatores extrínsecos (adubação e correção) não prejudicou o variograma a ponto de extinguir a estrutura dos que apresentaram moderado grau de dependência espacial, pois a altura e produção das plantas relacionou-se principalmente com fatores intrínsecos. (ARTUR et al., 2014; CAMBARDELLA, 1994) Segundo Oliveira et al. (2012) o impedimento físico oferece resistência a penetração de raízes, prejudicando $\mathrm{o}$ crescimento da parte aérea (OLIVEIRA, 2012), fato ocorrido na posição de ombro.

Os valores das variáveis saturação por bases, soma de bases, capacidade de troca cationnica e altura apresentam forte estacionalidade dentro de alcances curtos, variando entre 51,04 e $64,2 \mathrm{~m}$.
Este efeito pode ser melhor evidenciado pela análise de krigagem, as estratificações ilustradas nos mapas temáticos que são fortemente influenciadas por fatores intrínsecos principalmente pela profundidade efetiva do solo.

O forte grau de dependência espacial classificado segundo Zimback (2001) em todas as variáveis, com exceção do $\mathrm{pH}$ e perfilhos, pressupõe que a distribuição espacial das mesmas não são aleatórias. $\mathrm{O}$ alcance da dependência espacial é evidenciado na Tabela 3, que foi mais curto para todos os atributos químicos do solo, com exceção do $\mathrm{pH}$, que apresentou grau de dependência espacial moderado, consequentemente melhor campo estrutural variográfico.

Os mapas temáticos desenvolvidos através da análise de krigagem estão na Figura 3.

Verifica-se nos mapas que tanto a variabilidade dos atributos químicos do solo quanto o desempenho da forragem estão diretamente ligados à profundidade efetiva do solo.

A proximidade da superfície lítica fragmentária de avançado estágio de intemperização na posição de ombro e meia encosta fornece elevada disponibilidade de minerais secundários, o que eleva a quantidade de elementos em diferentes estágios de ionização, podendo afetar até o $\mathrm{pH}$, mas também funciona como barreira física e química para o desenvolvimento das raízes (BEUTER \& CENTURION, 2004; BONELLI et al., 2011).

O Neossolo Litólico apresenta físico e químico para o enraizamento das plantas em profundidade, alterando a profundidade efetiva e o dinamismo ecológico do solo (OLIVEIRA, 2001), além de elevada capacidade de erodibilidade. $\mathrm{O}$ maior entrave para $\mathrm{o}$ bom desenvolvimento das plantas foi a 
Rev. Bras. Saúde Prod. Anim., Salvador, v.16, n.4, p.772-783 out./dez.., 2015 http://www.rbspa.ufba.br ISSN 15199940

baixíssima profundidade efetiva $(0,17 \mathrm{~cm})$ (BONELLI et al., 2011) que, associada à elevada saturação por alumínio, pode provocar sérias restrições fisiológicas às plantas pela toxicidade do alumínio em excesso (YANLK \& VADAR 2015).

A variabilidade dos valores dos recursos forrageiros acompanha a distribuição dos fatores de produção, essenciais para seu ciclo de vida e produção revela os problemas de manejo que podem ocorrer em áreas declivosas e que precisam ser sanados ou amenizados através do estabelecimento de zonas de manejo.

Embora a posição de ombro, onde se localiza o Neossolo Litólico, apresente saturação por base acima de 51\%, capacidade de troca catiônica acima de $15 \%$ e soma de bases entre 9,5 e $6,7 \mathrm{cmol}_{\mathrm{c}} \mathrm{dm}^{-3}$, condições químicas coerentes para produção satisfatória em braquiária (KORNDÖFFER et al., 2010), a produção de matéria seca não ultrapassou $2280 \mathrm{~kg} \mathrm{ha}^{-1} \mathrm{e}$ altura de plantas foi menor que $32 \mathrm{~cm}$, isso demonstra que a profundidade efetiva foi determinante para redução da produção de matéria seca quando comparada as posições de topo e pedimento.

As maiores produções de matéria seca de forragem concentraram-se na porção superior do terreno, variando entre 2770 a $3750 \mathrm{~kg} \mathrm{ha}^{-1}$, enquanto que as posições mais declivosas, tais como a meia encosta e ombro, apresentaram valores mais baixos em relação ao topo. O topo apresenta maior profundidade efetiva. Analogamente a este trabalho, Garmeiro et al. (2009) encontrou produção de matéria seca inferior a $1823 \mathrm{~kg} \mathrm{ha}^{-1}$ nos locais onde a densidade do solo variava

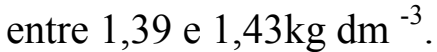

Tabela 3. Valores da análise geoestatística das variáveis químicas, profundidade efetiva do solo e das variáveis altura, produção de matéria seca e perfilhamento da forrageira da área cultivada com Uroclhoa brizantha cv. Marandu na profundidade $0-20 \mathrm{~cm}$

\begin{tabular}{lccccccc}
\hline Variáveis & Mod & $\mathrm{C}_{\mathrm{o}}$ & Patam. & $\mathrm{A}_{\mathrm{o}}$ & $\mathrm{C} /\left(\mathrm{C}_{\mathrm{o}}+\mathrm{C}\right)$ & $\mathrm{R}^{2}$ & GDE \\
\hline & \multicolumn{7}{c}{ Capim $0-20 \mathrm{~cm}$} \\
\hline $\mathrm{V}(\%)^{\mathrm{N}}$ & Esf. & 4,90 & 37,98 & 52,00 & 0,87 & 0,96 & Forte \\
$\mathrm{SB}^{\mathrm{N}}\left(\mathrm{cmol}_{\mathrm{c}} \mathrm{dm}^{-3}\right)$ & Esf. & 1,03 & 5,12 & 80,19 & 0,80 & 0,99 & Forte \\
$\left.\mathrm{CTC}^{\mathrm{N}} \mathrm{cmol}_{\mathrm{c}} \mathrm{dm}^{-3}\right)$ & Gau. & 2,78 & 23,23 & 108,94 & 0,88 & 0,99 & Forte \\
${\mathrm{m}(\%)^{\mathrm{N}}}^{\mathrm{N}}$ & Gau. & 10,8 & 175,2 & 97,1 & 0,93 & 0,99 & Forte \\
$\mathrm{pH}^{\mathrm{N}}\left(\mathrm{CaCl}_{2}\right)$ & Exp. & 0,02 & 0,05 & 76,00 & 0,62 & 0,95 & Mod \\
$\mathrm{MS}^{\mathrm{N}}\left(\mathrm{tha}^{-1}\right)$ & Gau. & 162000 & 849600 & 79,32 & 0,80 & 0,99 & Forte \\
Altura $^{\mathrm{N}}(\mathrm{cm})$ & Esf. & 3,39 & 25,52 & 115,30 & 0,86 & 0,99 & Forte \\
P. $\left(\mathrm{m}^{2}\right)$ & Esf. & 797,00 & 3082,00 & 44,00 & 0,74 & 0,64 & Mod \\
P.E. ${ }^{\mathrm{N}}(\mathrm{cm})$ & Esf. & 54,00 & 1481,00 & 89,70 & 0,96 & 0,99 & Forte \\
\hline V!:
\end{tabular}

$\mathrm{V}_{1}$ : saturação por bases, SB: Soma de Bases, CTC: Capacidade de Troca Catiônica, m: saturação por alumínio, MS: Matéria Seca $\mathrm{kg} \mathrm{ha}^{-1}$, P.: número de perfilhos $\mathrm{m}^{-2}$, altura $(\mathrm{cm})$, P.E.: Profundidade Efetiva do solo $(\mathrm{cm})$. Mod: Modelos: Exp: exponencial, Esf: esférico. $\mathrm{A}_{0}$ : alcance, $\mathrm{R}^{2}$ : coeficiente de determinação, $C / \mathrm{C}_{0}+\mathrm{C}_{1}$ : grau de dependência espacial, $\mathrm{C}_{0}$ : efeito pepita, GDE: classificação do grau de dependência espacial, segundo a classificação de Zimback (2001): Mod. moderado. 
Rev. Bras. Saúde Prod. Anim., Salvador, v.16, n.4, p.772-783 out./dez.., 2015 http://www.rbspa.ufba.br
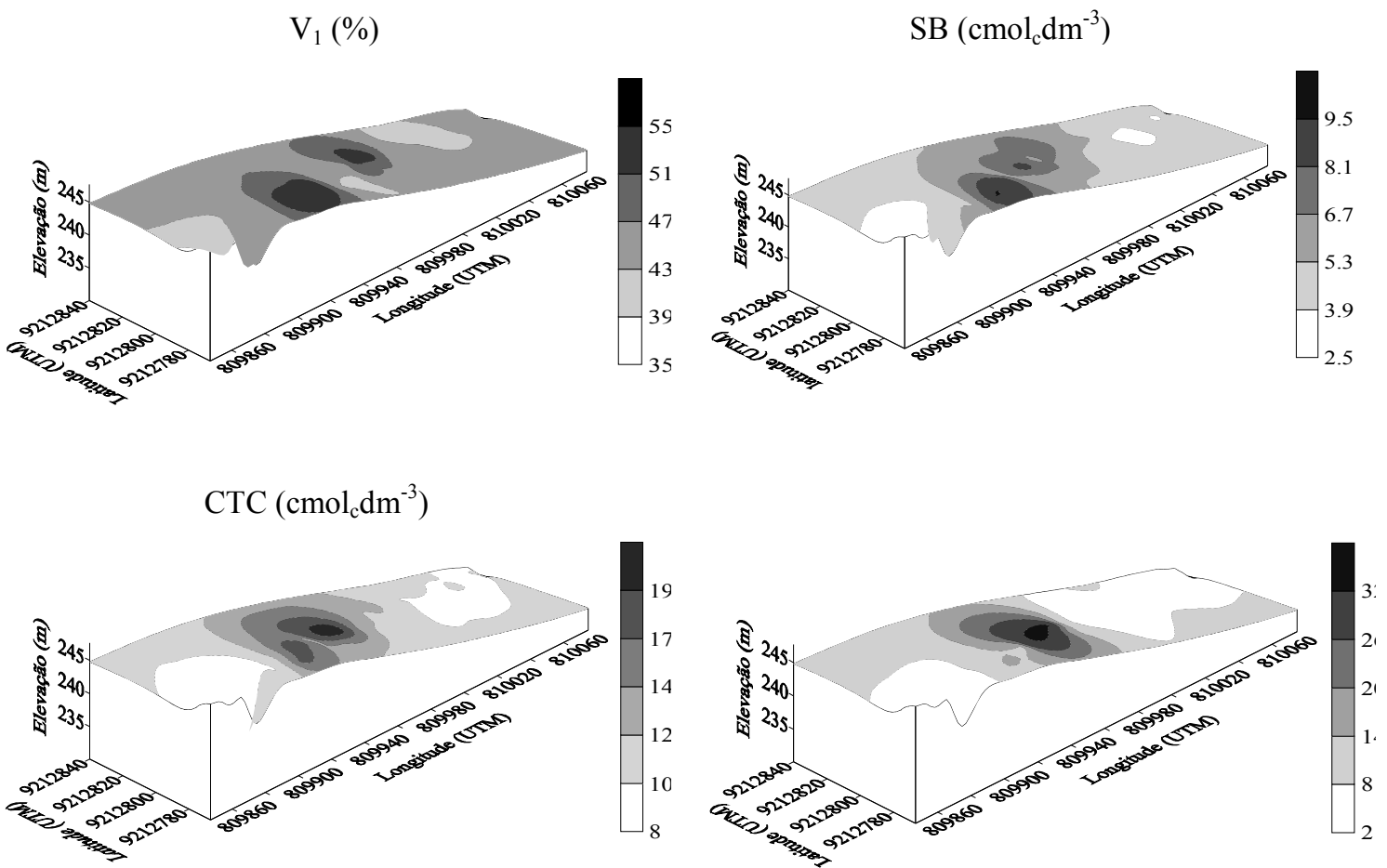

$\mathrm{pH}$

$\operatorname{MS}\left(\mathrm{kg} \mathrm{ha}^{-1} /\right.$ ciclo $)$
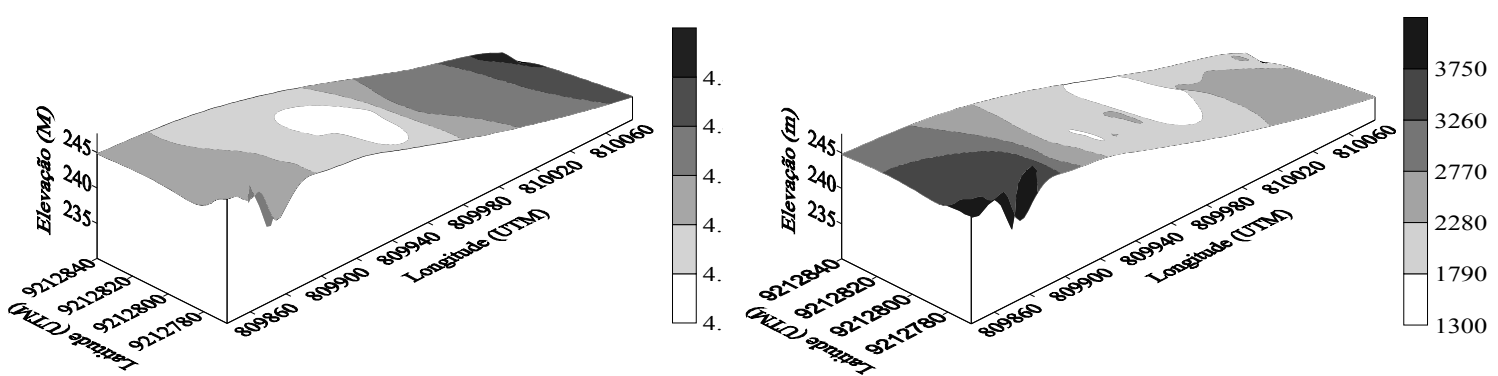

Profundidade efetiva $(\mathrm{cm})$

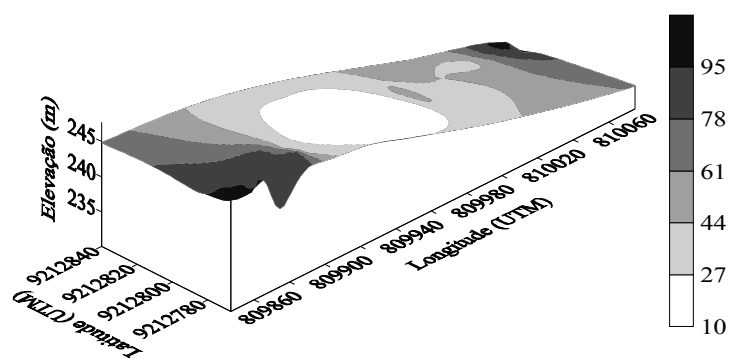

Figura 3. Mapas de isolinhas das propriedades químicas do solo na profundidade de 0-20cm e das variáveis de agronômica e morfológica da forrageira em área cultivada com pastagem de capim-braquiária. Posição do terreno, Longitudes entre 809840 e 809920 representa o topo, 809920 e 809940 o ombro, 809940 e 810020 meia encosta e representando o pedimento 810020 e 810040 UTM. Escala 1:50 
Rev. Bras. Saúde Prod. Anim., Salvador, v.16, n.4, p.772-783 out./dez.., 2015 http://www.rbspa.ufba.br

A produtividade e a altura do pasto foram superiores no topo aos 32 dias após o pastejo $(35$ e $40 \mathrm{~cm})$ em relação às demais posições do terreno. A forrageira cultivada no ombro foi a mais prejudicada, com altura variando entre 27 e $30 \mathrm{~cm}$. A baixa produtividade na posição do ombro deve-se a baixa profundidade efetiva do solo. Concomitantemente, o manejo de pastagens baseia-se na estrutura vertical do dossel para entrada e saída de animais. (GOMES et al., 2009) Em terrenos declivosos, pode apresentar elevada discrepância no aproveitamento do pasto, visto que a heterogeneidade dos atributos do solo influencia a produtividade e crescimento das plantas. Consequentemente, as variações observadas na forrageira neste tipo de terreno deveriam ser inseridas dentro do manejo de pastagem, para melhor divisão de piquetes.

O dossel forrageiro apresenta heterogeneidade na morfologia em função da distribuição espacial da fertilidade do solo e da profundidade efetiva.

A análise química e de profundidade efetiva do solo mostraram que podem ser vistas como prenúncio ao manejo do pasto, que por sua vez poderá ser ajustado de acordo com as especificidades relativas às condições topográficas.

O horizonte agrícola das posições de ombro e meia encosta foram menos produtivas para capim Marandu, definindo uma zona de manejo diferente do topo e pedimento.

\section{REFERÊNCIAS}

ARTUR, A.G.; OLIVEIRA, D.P.; COSTA, M.C.G.; ROMERO, R.E.; SILVA, M.V.C.; FERREIRA, T. O. Variabilidade espacial dos atributos químicos do solo, associada ao microrrelevo. Revista Brasileira de Engenharia Agrícola Ambiental, v.18, n.2, p.141-149, 2014.
BEUTLER, A.N.; CENTURION, J.F.

Compactação do solo no desenvolvimento radicular e na produtividade da soja, Pesquisa Agropecuária Brasileira, v.39, n.6, p.581-588, 2004.

BONELLI, E.A.; BONFIM-FILHO, E.M.; CABRAL, C.E.A.; CAMPOS, J.J.; SCARAMUZZA, W.L.M.; POLIZEL, A.C. Compactação do solo: efeitos nas características produtivas e morfológicas dos capins Piatã e Mombaça, Revista Brasileira de Engenharia Agrícola e Ambiental, v.15, n.3, p.264-269, 2011.

CAMBARDELLA, C.A.; MOORMAN, T.B.; NOVAK, J.M.; PARKIN, T.B.; KARLEN, D.L.; TURCO, R.F.; KONOPKA, A.E. Field-scale variability of soil properties in central Iowa soils.

Soil Science Society of America Journal, v.58, n.4, p.1501-1511, 1994.

CAMPOS, M.C.C.; FERRAZ, F.B.; ERIBERTO, V.S. F.; SOUZA, Z.M. Dependência espacial de atributos físicos e hídricos de espodossolo da zona da mata de Pernambuco. Revista de Biologia e Ciências da Terra, v.7, n.1, 2007.

CAVALLINI, M.C.; ANDREOTTI, M.; OLIVEIRA, L.L.; PARIZ, C.M.; CARVALHO, M.P. Relações entre produtividade de Brachiaria brizantha e atributos físicos de um Latossolo do cerrado. Revista Brasileira de Ciência do Solo, v.34, n.4, p.1007-1015, 2010.

DAVATGAR, N.; NEISHABOURI, M. R.; SEPASKAH, A.R., Delineation of site specific nutriente management zones for a paddy cultivated área based on soil fertility using fuzzy clustering, Geoderma, v.173-174, n.2, p.111-118, 2012. 
Rev. Bras. Saúde Prod. Anim., Salvador, v.16, n.4, p.772-783 out./dez.., 2015 http://www.rbspa.ufba.br ISSN 15199940

EMBRAPA. Centro Nacional de Pesquisa em Solos. Sistema Brasileiro de Classificação de Solos. 2 ed. Brasília, DF, 2006. 306 p.

EMBRAPA. Centro Nacional de Pesquisa em Solos. Manual de análises química de solos, plantas e fertilizantes. 1 ed. Brasília, DF, 1999. $256 \mathrm{p}$.

GARMEIRO, R.A.; ANDREOTTI, M.; PARIZ C.M.; CARVALHO, M.P.; MONTANARI, R. Variabilidade espacial da produtividade da forragem de Braquiária e atributos físicos de um Latossolo do cerrado brasileiro. In: CONGRESSO DE INICIAÇÃO CIENTÍFICA DA UNESP, 2009, São José do Rio Preto.. Anais... São José do Rio Preto: UNESP, 2009. p.108-112.

GOMES, V.M.; SANTOS, M.E.R.; SILVA, S.P.; FONSECA, D.M.; SILVA, G.P; SANTO, A.L. Variabilidade espacial da vegetação durante a utilização do pasto diferido de capim-braquiária. In: Zootec, 2009, Águas de Lindóia. Anais... Águas de Lindóia: ABZ, 2009.

KORNDÖRFER, P.H.; DA SILVA, G.C.; TEIXEIRA, I.R.; DA SILVA, A.G.; DE FREITAS, R.S. Efeito da adubação silicatada sobre gramíneas forrageiras e características químicas do solo, Pesquisa Agropecuária Tropical. v.40, n.2, p.119-125, 2010.

ISAAKS, E. H.; SRIVASTAVA, R.M. An introduction to applied geoestatistics. New York: Oxford University Press, 1989. 561p.

MIGUEL, F.R.M.; VIEIRA, S.R.; GREGOR, C.R. Variabilidade espacial da infiltração de água em solo sob pastagem em função da intensidade de pisoteio, Pesquisa Agropecuária Brasileira, v.44, n.11, p.1513-1519, 2009.
OLIVEIRA, J.B. Pedologia aplicada. Jaboticabal: FUNEP, 2001. 414p.

OLIVEIRA, P.R.; CENTURION, J.F.; CENTURION, M.A.P. C.; FRANCO, H.B.J.; PEREIRA, F.S.; BÁRBARO JÚNIOR, L.S.; ROSSETTI K. V. Qualidade física de um Latossolo Vermelho cultivado em soja submetido a níveis de compactação e de irrigação, Revista Brasileira de Ciência do Solo, v.36, n.2, p.587-597, 2012.

PARFITT, J.M.; TIMM, L.C.; ELOY, A.P.; SOUSA, R.O.; CASTILHO, D.D.; ÁVILA, C.L.; RCKZIEGEL, N.L. Spatial variability of the chemical, physical and biological properties in lowland cultivates with irrigated rice. Revista Brasileira de Ciência do Solo, v.33, n.4, p.819-830, 2009.

ROBERTSON, G.P. GS+:

Geoestatistic for the environmental science- GS+ User's guide. Plainwell: Gamma Design Software, 1998. 152p.

SANTOS, M.E.R.; FONSECA, D.M.; BALBINO, E.M.; SILVA, S.P.; MONNERAT, J.P.I.S. Variabilidade espacial e temporal da vegetação em pastos de capim-braquiária deferidos. Revista Brasileira de Zootecnia, v.39, n. 4, p.727-735, 2010.

SCHWARTZ, F.; ROCHA, M.G.; VÉRAS, M; FARINATTI, L.H.; PIRES, C.C.; CELLA JUNIOR, A.A. Manejo de milheto (Pennnisetum americanum Leeke) sob pastejo de ovinos. Revista Brasileira de Agrociências, v.9, n.2, p.151-155, 2003.

ZANÃO JÚNIOR, L.A.; LANA, R.M.Q.; GUIMARÃES, E.C.; PEREIRA, J.M.A.Variabilidade espacial de nutrientes em Latossolo sob sistema plantio direto. Revista Brasileira de Ciência do Solo, v.34, n.5, p.389-400, 2010. 
Rev. Bras. Saúde Prod. Anim., Salvador, v.16, n.4, p.772-783 out./dez.., 2015 http://www.rbspa.ufba.br ISSN 15199940

ZIMBACK, C.R.L. Análise espacial de atributos químicos de solos para fins de mapeamento da fertilidade do solo. 2001, 114f. Tese (Livre-Docência em levantamento do solo e fotopedologia) Universidade Estadual Paulista, Botucatu.

YANLK, F.; VARDAR, F. Toxic effects of aluminuim oxide (A12O3) nanoparticles on root growth and development in Triticum aestivum, Water Air Soil Pollut, v.226, n.9, p.113, 2015.

Data de recebimento: $24 / 09 / 2014$

Data de aprovação: 23/09/2015 